\title{
A Single Nonlinear Current Control for PWM Rectifier Robust to Input Disturbances and Dynamic Loads
}

\author{
Nancy Visairo-Cruz, ${ }^{1}$ Ciro Núñez-Gutiérrez, ${ }^{1}$ Eliseo Alcázar, ${ }^{2}$ and Elías Rodríguez ${ }^{3}$ \\ ${ }^{1}$ Faculty of Engineering, Universidad Autónoma de San Luis Potosí, 78290 San Luis Potosí, SLP, Mexico \\ ${ }^{2}$ Schweitzer Engineering Laboratories, S.A. de C.V., 78395 San Luis Potosí, SLP, Mexico \\ ${ }^{3}$ Instituto Tecnológico de Celaya, Celaya, GTO, Mexico \\ Correspondence should be addressed to Nancy Visairo-Cruz; nvisairoc@uaslp.mx
}

Received 22 June 2017; Accepted 24 October 2017; Published 19 November 2017

Academic Editor: Ivan Giorgio

Copyright (C) 2017 Nancy Visairo-Cruz et al. This is an open access article distributed under the Creative Commons Attribution License, which permits unrestricted use, distribution, and reproduction in any medium, provided the original work is properly cited.

\begin{abstract}
The requirements of PWM rectifiers for delivering power to motor drives include power factor correction and output voltage regulation even when strong variations such as voltage sags and dynamic load transients occur simultaneously. To achieve these objectives, the classic approach is to use a two-loop controller with its $d-q$ model. In this paper, the authors propose a simplified approach to address that problem by using a feedback linearization-based nonlinear controller using only a single-loop current control and avoiding $d-q$ modeling to reduce processing stages. To demonstrate the feasibility of this approach, several simulations are presented considering a $1.5 \mathrm{~kW}$ PWM rectifier.
\end{abstract}

\section{Introduction}

The analysis of the PWM rectifiers is a very well-studied topic in both single-phase and three-phase applications due to its many advantages from the power electronics standpoint [13]. So, there is a lot of technical background related to it and most documented papers use a two-loop control scheme to obtain an adequate system performance, where the first loop is meant to control current with fast dynamics and the second one is meant to control output voltage with slow dynamics [4-12].

Also, several papers report the use of synchronous $d-q$ frame transformation in order to calculate the compensation references $[13,14]$. Besides, it is also usual to use $d$-q modeling for the control design. One powerful reason is that the tracking problem required in time domain is converted into a regulation problem in a $d-q$ synchronous frame [15], which is a common practice, although it implies a certain degree of delay due to the transformation itself.

Considering the aforementioned, several nonlinear control schemes have been proposed in the literature in the last two decades in order to obtain the desired benefits of the topology, which include power factor correction, harmonic compensation, and, as an extended property, voltage sag ride through [16-22], in spite of the fact that these techniques are as old as feedback control [23].

Nevertheless, this paper analyzes the PWM rectifier with a different approach. Firstly, the $d-q$ transformation is not used either to obtain references or to convert the system model from time domain to $d$ - $q$ domain. When a controller is tuned in $d-q$ domain, the system should be perfectly synchronized with the AC mains and each stage dedicated to the $d-q$ conversion and to the $d$-q-inverse conversion should maintain this synchronization. If AC mains have frequency variations of $\pm 3 \%$, the $d$ - $q$ conversion can fail even with smaller variations. However, with the controller proposed in this paper, this synchronization is avoided in each stage and the tracking problem is solved directly in time domain. Secondly, the use of two-loop control is avoided, considering only a single-loop current control by using a nonlinear controller based on its input-output linearization via feedback. The two above-mentioned points are considered in order to facilitate a fast dynamic response and to avoid overprocessing. 
TABLE 1: Approaches reported in literature versus proposed approach.

\begin{tabular}{|c|c|c|}
\hline Concept & Reported approaches & Proposed approach \\
\hline$d-q$ transformation & $\sqrt{ }$ & $\times$ \\
\hline Control theory & Linear and nonlinear & Nonlinear \\
\hline Current control loop & $\sqrt{ }$ & $\sqrt{ }$ \\
\hline Voltage control loop & $\sqrt{ }$ & $\times$ \\
\hline Load dynamics & $\begin{array}{l}\text { Usually resistive with load } \\
\text { steps }\end{array}$ & $\begin{array}{l}\text { Nonlinear, different patterns of current } \\
\text { consumption, with load steps }\end{array}$ \\
\hline Robustness for source sags & $\sqrt{ }$ & $\sqrt{ }$ \\
\hline Analysis complexity & Medium & Medium \\
\hline
\end{tabular}

TABLE 2: Switching combination for the single-phase PWM rectifier circuit.

\begin{tabular}{lccccccc}
\hline Mode & $Q_{1}$ & $Q_{2}$ & $Q_{3}$ & $Q_{4}$ & $s w_{1}$ & $s w_{2}$ & $V_{a^{\prime} b^{\prime}}$ \\
\hline I & 0 & 1 & 0 & 1 & 1 & 1 & 0 \\
II & 0 & 1 & 1 & 0 & 0 & 1 & $-I_{\mathrm{DC}}$ \\
III & 1 & 0 & 0 & 1 & 1 & 0 & $-V_{\mathrm{DC}}$ \\
IV & 1 & 0 & 1 & 0 & 0 & 0 & $+V_{\mathrm{DC}}$ \\
\hline
\end{tabular}

Now, the control objectives are to regulate the output voltage, to maintain power factor near to unity, and to achieve a sinusoidal current waveform even when voltage sags and dynamic load transients operate simultaneously, with an unexpected pattern. To highlight the new characteristics of the proposed control approach in this paper, Table 1 presents its main characteristics compared against those approaches reported in the literature related to the use of the $d-q$ transformation and the control schemes with two loops.

Then, the development of the paper is organized as follows: Section 2 is dedicated to the development of the model of the PWM rectifier and showing the capabilities of the system. After that, in Section 3, the closed-loop system using the proposed control scheme is analyzed. In Section 4, simulations of the system considering two nonlinear loads with different profiles of current consumption appearing at different times and unexpected voltage sags are developed in order to show the benefits of this proposal. Finally, in Section 5, the authors state their conclusions of this research.

\section{Single-Phase PWM Rectifier Modeling}

In this section, the single-phase PWM rectifier model is presented. Figure 1 shows a typical single-phase rectifier circuit, with power factor correction capability.

Table 2 summarizes all the possible switching combinations for the single-phase PWM rectifier and their corresponding created full-bridge voltage, $V_{a^{\prime} b^{\prime}}$. Switches $s w_{1}$ and $s w_{2}$ are created to simplify the model analysis and besides it is considered that $V_{a^{\prime} b^{\prime}}=V_{\mathrm{DC}}\left(s w_{1}-s w_{2}\right) ; I_{\mathrm{DC}}=i_{L}\left(s w_{1}-s w_{2}\right)$; and $s w_{1}, s w_{2} \in\{1,0\}$.

Based on previous considerations, analysis leads to the equivalent circuit shown in Figure 2 , where $d_{12}=\left(d_{1}-d_{2}\right)$ with $d_{1} \in[1,0], d_{2} \in[1,0]$, and $d_{12} \in[-1,1]$.

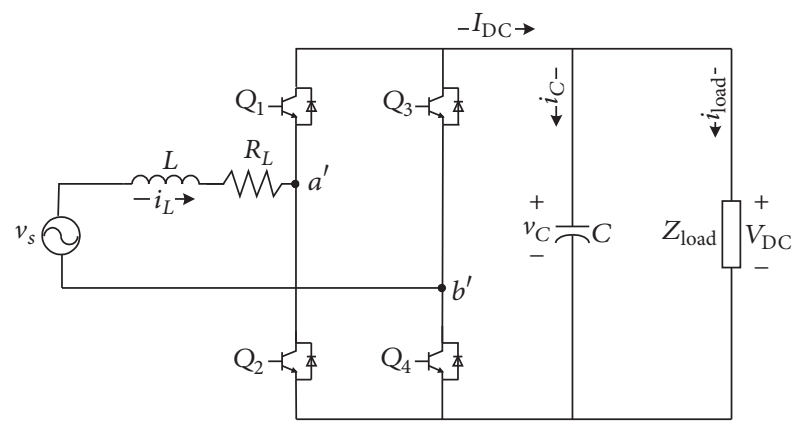

FIGURE 1: Single-phase PWM rectifier circuit.

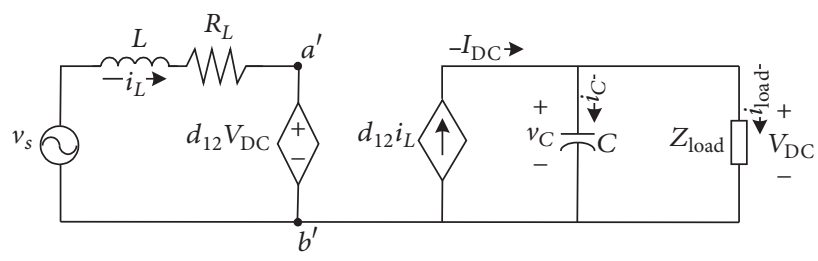

FIGURE 2: Simplified equivalent circuit of the single-phase PWM rectifier.

By doing the circuit analysis, the mathematical model of the system can be obtained:

$$
\begin{aligned}
\frac{d i_{L}}{d t} & =-\frac{R_{L}}{L} i_{L}-\frac{1}{L} d_{12} v_{C}+\frac{1}{L} v_{s}, \\
\frac{d v_{C}}{d t} & =\frac{1}{C} d_{12} i_{L}-\frac{1}{C Z_{\text {load }}} v_{C} .
\end{aligned}
$$


TABLE 3: System test conditions.

\begin{tabular}{ll}
\hline Parameter & Value \\
\hline$v_{s}(t)$ & $180 \sin (\omega t)$ \\
$V_{\mathrm{DC}}$ & $200 \mathrm{~V}$ \\
$P_{\text {load }}$ & $1500 \mathrm{~W}$ \\
Power factor & Near to unity \\
Maximum ripple in steady state & $10 \%$ \\
Maximum overshoot in transient state & $15 \%$ \\
Switching frequency & $20 \mathrm{kHz}$ \\
& Two inverters connected at different time: the first one of $750 \mathrm{~W}$, switching frequency of $1 \mathrm{kHz}$, \\
Load & and output frequency of $60 \mathrm{~Hz}$ with $0^{\circ}$ of phase shift and the second one of $750 \mathrm{~W}$, switching \\
& frequency of $1.5 \mathrm{kHz}$, and output frequency of $50 \mathrm{~Hz}$ with $30^{\circ}$ of phase shift \\
\hline
\end{tabular}

Then, considering the state variables,

$$
\begin{aligned}
{\left[\begin{array}{l}
i_{L} \\
v_{C}
\end{array}\right] } & =\left[\begin{array}{l}
x_{1} \\
x_{2}
\end{array}\right], \\
d_{12} & =u .
\end{aligned}
$$

Next, the state space system representation is attained:

$$
\begin{aligned}
& \dot{x}_{1}=-\frac{R_{L}}{L} x_{1}-\frac{1}{L} u x_{2}+\frac{1}{L} v_{s}, \\
& \dot{x}_{2}=\frac{1}{C} u x_{1}-\frac{1}{C Z_{\text {load }}} x_{2},
\end{aligned}
$$

where $Z_{\text {load }}=V_{\mathrm{DC}} / i_{\text {load }}$

Table 3 summarizes system specifications. It is worth mentioning that the initial analysis considers a maximum power capability of $1.5 \mathrm{~kW}$ as well as a highly dynamic load that does not exceed the maximum power limits. In order to obtain all the physical variables involved in the control loop, all sensors are considered available. However, these are the typical sensors used in power electronics applications, which means that there is no additional hardware with regard to other proposals.

\section{Single-Phase PWM Rectifier Closed-Loop System}

Before starting the design of the controller, it is important to establish clearly the control objectives, which always should be associated with the physical capabilities of the system [24]. From this point of view, the control objectives are the following:

(a) To regulate the output voltage $v_{C}$, which can be achieved considering the maximum power specified in Table 3. This condition should be maintained even when dynamic loads and input voltage sags occur simultaneously at unexpected times. The physical limitation is related to the amount of current that can be transferred by the PWM rectifier from the AC side to the DC side. Said amount of current is controlled by duty cycle (b) To compensate the power factor

(c) To eliminate harmonic current, which means that the desired current waveform of $i_{L}$ should be sinusoidal and in phase with the voltage $v_{s}$

3.1. Feedback Linearization-Based Nonlinear Control. Consider the single-input-single-output system

$$
\begin{aligned}
& \dot{\mathbf{x}}=f(\mathbf{x})+g(\mathbf{x}) u, \\
& y=h(\mathbf{x}),
\end{aligned}
$$

where $f, g$, and $h$ are sufficiently smooth functions in a domain $D \in \mathfrak{R}^{n}$ and the mappings $f: D \rightarrow \mathfrak{R}^{n}$ and $g: D \rightarrow \Re^{n}$ are called vector fields on $D[25,26]$. Consider also the relative degree $\rho$ as the number of derivates of the output to find the input. If $\rho<n$, then a diffeomorphism restricted to a neighborhood $N$ can be built as

$$
\mathbf{z}=T(\mathbf{x})=\left[\begin{array}{c}
\phi_{1}(\mathbf{x}) \\
\vdots \\
\phi_{n-\rho}(\mathbf{x}) \\
\cdots \\
h(\mathbf{x}) \\
\vdots \\
L_{f}^{\rho-1} h(\mathbf{x})
\end{array}\right]=\left[\begin{array}{l}
\eta \\
\xi
\end{array}\right],
$$

where $\eta \in \mathfrak{R}^{n-\rho}, \xi \in \mathfrak{R}^{\rho}$, and $\phi_{i}$ for $i=1, \ldots, n-\rho$ must satisfy

$$
\frac{\partial \phi_{i}(\mathbf{x})}{\partial \mathbf{x}} g(\mathbf{x})=0, \quad \text { for } 1 \leq i \leq n-\rho, \forall x \in D_{0}
$$

with $D_{0} \subset D$. Then, (4) can be expressed in its normal form given by

$$
\begin{aligned}
& \dot{\eta}=f_{0}(\eta, \xi), \\
& \dot{\xi}=A_{c} \xi+B_{c} \gamma(\mathbf{x})[u-\alpha(\mathbf{x})], \\
& y=C_{c} \xi,
\end{aligned}
$$




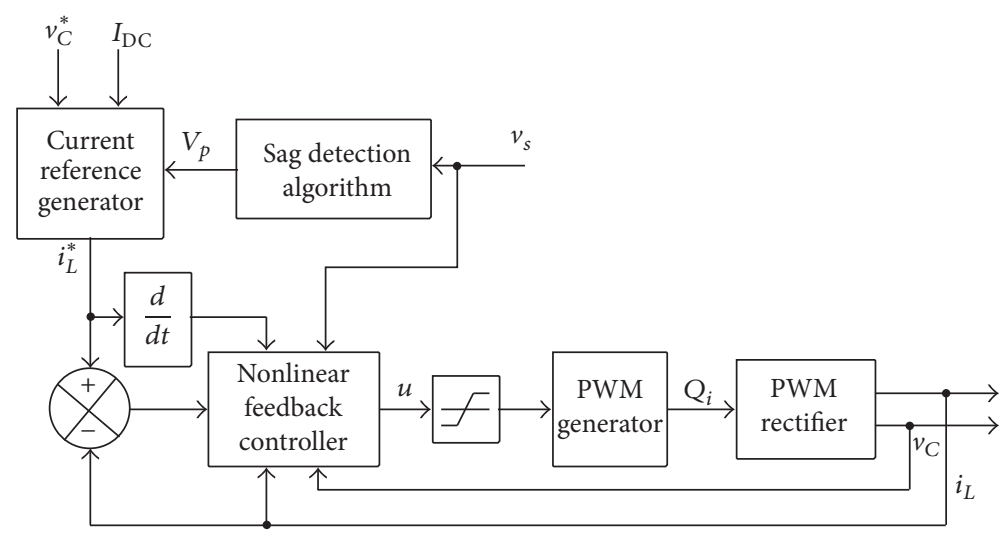

Figure 3: Proposed closed-loop control for the single-phase PWM rectifier.

where $\left(A_{c}, B_{c}, C_{c}\right)$ is a canonical form representation and

$$
\begin{gathered}
f_{0}(\eta, \xi)=\left.\frac{\partial \phi(\mathbf{x})}{\partial \mathbf{x}} f(\mathbf{x})\right|_{\mathbf{x}=T^{-1}(\mathbf{z})}, \\
\alpha(\mathbf{x})=-\frac{L_{f}^{\rho} h(\mathbf{x})}{L_{g} L_{f}^{\rho-1} h(\mathbf{x})}, \\
\gamma(\mathbf{x})=L_{g} L_{f}^{\rho-1} h(\mathbf{x}) .
\end{gathered}
$$

Equation (7) is formed by an external part $\xi$ and an internal part $\eta$. The external part can be linearized by the controller

$$
u=\alpha(\mathbf{x})+\beta(\mathbf{x}) v
$$

with $\beta=\gamma^{-1}(\mathbf{x})$ and $v=-\mathbf{k x}$. Meanwhile, the zero dynamics

$$
\dot{\eta}=f_{0}(\eta, 0)
$$

must be asymptotically stable; that is, the system must be of minimum phase.

3.2. Design of the Nonlinear Controller. Then, according to the control objectives and the feedback linearization-based nonlinear control theory, a tracking problem of the current $i_{L}$ will be the study objective. For this, the error dynamics of the system should be considered. So, the proposed closed-loop system to be designed is depicted in Figure 3, which consists of a sag detection algorithm, a reference generator, and the single-loop nonlinear controller.

Based on the state space representation (3),

$$
\begin{aligned}
& f(\mathbf{x})=\left[\begin{array}{c}
-\frac{R_{L}}{L} x_{1}+\frac{1}{L} v_{s} \\
-\frac{1}{C Z_{\text {load }}} x_{2}
\end{array}\right], \\
& g(\mathbf{x})=\left[\begin{array}{c}
-\frac{1}{L} x_{2} \\
\frac{1}{C} x_{1}
\end{array}\right],
\end{aligned}
$$

and it can be verified that the system is input-output linearizable with relative degree $\rho=1$ for $y=x_{1}$ with

$$
\dot{y}=\dot{x}_{1}=-\frac{R_{L}}{L} x_{1}-\frac{1}{L} u x_{2}+\frac{1}{L} v_{s} .
$$

Then, the following diffeomorphism can be built:

$$
\mathbf{z}=\left[\begin{array}{c}
T_{1}(\mathbf{x}) \\
T_{2}(\mathbf{x})
\end{array}\right]=\left[\begin{array}{c}
\phi_{1}(\mathbf{x}) \\
h(\mathbf{x})
\end{array}\right]=\left[\begin{array}{l}
\eta \\
\xi
\end{array}\right]=\left[\begin{array}{c}
\frac{L x_{1}^{2}+C x_{2}^{2}}{C} \\
x_{1}
\end{array}\right],
$$

defined $\forall \mathbf{x} \in \mathfrak{R}^{2} \mid x_{2} \neq 0$, and it is possible to achieve its normal form (7) as

$$
\begin{aligned}
& \dot{\eta}=-\frac{2 R_{L}}{C} \xi^{2}+\frac{2 L}{C^{2} Z_{\text {load }}} \xi^{2}-\frac{2}{C Z_{\text {load }}} \eta+\frac{2}{C} v_{s} \xi, \\
& \dot{\xi}=-\frac{x_{2}}{L}\left[u-\frac{v_{s}-R_{L} x_{1}}{x_{2}}\right], \\
& y=\xi,
\end{aligned}
$$

where $\eta \in \mathfrak{R}^{1}, \xi \in \mathfrak{R}^{1}$, and

$$
f_{0}(\eta, \xi)=-\frac{2 R_{L}}{C} \xi^{2}+\frac{2 L}{C^{2} Z_{\text {load }}} \xi^{2}-\frac{2}{C Z_{\text {load }}} \eta+\frac{2}{C} v_{s} \xi
$$

with

$$
\mathbf{x}=T^{-1}(\mathbf{z})=\left[\begin{array}{l}
x_{1} \\
x_{2}
\end{array}\right]=\left[\begin{array}{c}
\xi \\
\left(\frac{C \eta-L \xi^{2}}{C}\right)^{1 / 2}
\end{array}\right],
$$

$$
\begin{aligned}
\alpha(\mathbf{x}) & =\frac{v_{s}-R_{L} x_{1}}{x_{2}}, \\
\gamma(\mathbf{x}) & =-\frac{x_{2}}{L}, \\
A_{c} & =[0], \\
B_{c} & =[1], \\
C_{c} & =[1] .
\end{aligned}
$$


Then, its internal dynamics is governed by

$$
\dot{\eta}=-\frac{2}{C Z_{\text {load }}} \eta,
$$

which means that the zero dynamics of the system is stable; so the nonlinear system is of minimum phase with positive $Z_{\text {load }}$ and $C$.

As previously stated, one of the control objectives is the power factor correction. Therefore, the control problem is to track the reference $i_{L}^{*}$. Besides, consider the following:

(i) Reference current $i_{L}^{*}$ and its derivative $i_{L}^{*}$ are bounded for every $t \geq 0$ and $i_{L}^{*}$ is piecewise continuous in $t$.

(ii) Signals $i_{L}^{*}$ and $i_{L}^{*}$ are available.

Then, considering its error dynamics, the tracking control law for the PWM rectifier system is given by

$$
u=\alpha(\mathbf{x})+\frac{1}{\gamma(\mathbf{x})}\left\{-k\left(T_{2}(\mathbf{x})-i_{L}^{*}\right)+i_{L}^{*}\right\} .
$$

The value of $k=13000$ is calculated such that $A_{c}-B_{c} k$ is to be Hurwitz for $v=-k\left(\xi-\xi^{*}\right)$. Then the tracking control law designed for (1) is

$$
d_{12}=\frac{v_{s}-R_{L} i_{L}}{v_{C}}-\frac{L}{v_{C}}\left\{-13000\left(i_{L}-i_{L}^{*}\right)+i_{L}^{*}\right\} .
$$

So, the current tracking is achieved asymptotically for all $t$ which can be seen in Section 4 .

As a part of the design, a sensor that measures $I_{\mathrm{DC}}$ is included. Now, based on the fact that one of the control objectives is to regulate the DC output voltage in $200 V_{\mathrm{DC}}$, this measurement is used to instantaneously calculate the reference to be supplied to the controller. In this way, it is possible to use only one feedback loop $i_{L}-i_{L}^{*}$ as (19) specifies. Also consider that measurements of voltage and current are needed, as in any other control scheme.

The system parameters are $L=1 \mathrm{mH}, R_{L}=1 \Omega$, and $C=1200 \mu \mathrm{F}$. These values can be calculated using any of the procedures reported in power converters literature taking into account the maximum power and the switching frequency proposed in this paper.

3.3. Reference Current Generator. In order to generate the reference signal $i_{L}^{*}$, the AC power on the source voltage side is considered equal to the power on the DC side; from this, it can be obtained that

$$
\begin{aligned}
P_{\mathrm{AC}} & =\frac{V_{p} I_{p}}{2}=P_{\mathrm{DC}}=V_{\mathrm{DC}} I_{\mathrm{DC}}, \\
\frac{V_{p} I_{p}}{2} & =V_{\mathrm{DC}} I_{\mathrm{DC}}, \\
I_{p}^{*} & =\frac{2 v_{C}^{*} I_{\mathrm{DC}}}{V_{p}},
\end{aligned}
$$

where $V_{p}$ and $I_{p}$ are the peak values of $v_{s}$ and $i_{L}$, respectively, and $V_{\mathrm{DC}}=v_{\mathrm{C}}^{*}$.
Since the current is in phase with the source voltage $v_{s}$ in order to have a unitary power factor,

$$
\begin{aligned}
& i_{L}^{*}=I_{p}^{*} \sin (2 \pi f t), \\
& i_{L}^{*}=2 \pi f I_{p}^{*} \cos (2 \pi f t) .
\end{aligned}
$$

So, based on (21), it can be concluded that $i_{L}^{*}$ satisfies the considerations previously stated for it.

\section{Simulation Results}

In this section, a set of simulation tests is presented considering the operational conditions described in Table 3. The application of this nonlinear control scheme demonstrates how the system achieves the performance and control objectives imposed as a part of the design. Considering Figure 4, the tests were performed as follows:

(i) The simulator used was Simulink of MATLAB applying ODE15s as integration method with a maximum integration step of $1 \mu \mathrm{s}$.

(ii) The sequence of tests is as follows: from $0 \mathrm{~s}$ to $0.1 \mathrm{~s}$, the PWM rectifier is functioning as an uncontrolled rectifier. This period of time is identified as Region I.

(iii) From $0.1 \mathrm{~s}$ to $0.2 \mathrm{~s}$, the PWM rectifier operates as a power factor corrector and reaches steady state. During this time, the load is a $750 \mathrm{~W}$ power inverter with switching frequency of $1 \mathrm{kHz}$, modulation index $m=0.9$, and output voltage at $60 \mathrm{~Hz}$ with zero degrees of phase shift. This period of time is identified as Region II.

(iv) A voltage sag to $75 \%$ occurs at $0.2 \mathrm{~s}$. The time between $0.2 \mathrm{~s}$ and $0.3 \mathrm{~s}$ is identified as Region III.

(v) At time $0.3 \mathrm{~s}$, an additional power inverter of $750 \mathrm{~W}$ with switching frequency of $1.5 \mathrm{kHz}$, modulation index $m=0.6$, and output voltage at $50 \mathrm{~Hz}$ with thirty degrees of phase shift is connected. The voltage sag continues. The time between 0.3 and $0.4 \mathrm{~s}$ is identified as Region IV.

(vi) At time $0.4 \mathrm{~s}$, the voltage sag ends, but the two inverters with $1.5 \mathrm{~kW}$ of consumption remain connected. The time between 0.4 and $0.5 \mathrm{~s}$ is identified as Region V.

Figure 5 shows the evolution of all regions mentioned above. The voltage supplied to the PWM rectifier $v_{s}$ is shown on (a), while on (b) the reference current $i_{L}^{*}$ and the AC current consumption of the system are plotted. It can be noticed that in Region I both signals are different because the system is working as a noncontrolled rectifier; however, once Region II is reached, the current consumption is sinusoidal and is in phase with the voltage during the rest of the test, which means that at all times power factor correction and harmonic elimination are achieved.

A general scope of the system performance is shown in Figure 6, where the current consumption of the nonlinear load based on power inverters connected as described for 


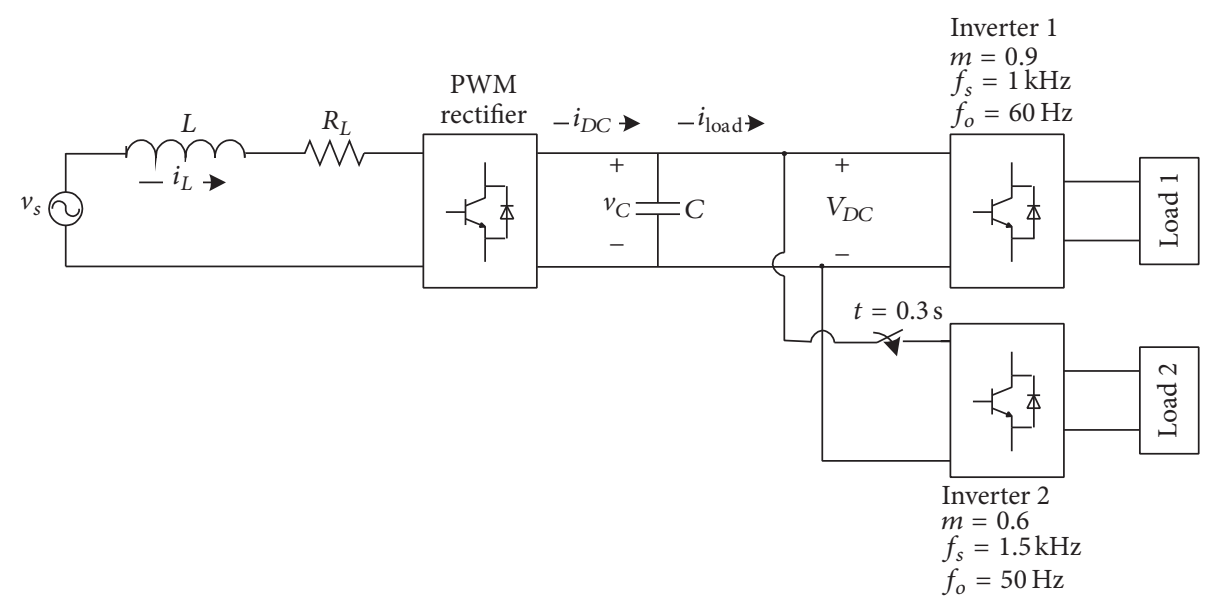

FIgURE 4: Test scheme to evaluate the performance of the closed-loop system.

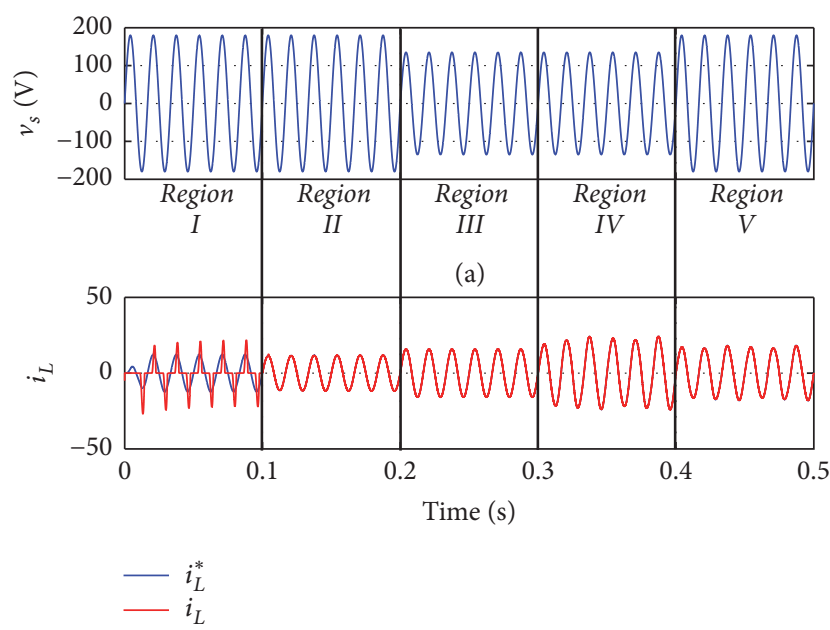

(b)

FIGURE 5: (a) Voltage delivered by the grid to the PWM rectifier. (b) Reference current and current consumption of the system.

each region can be observed on (a). On (b), the grid voltage supplied to the system with voltage sags events, the current consumption of the PWM rectifier, and the output DC voltage are plotted. It is important to notice that while in Region I the DC voltage is regulated at $180 \mathrm{~V}$ (because the system is working as a noncontrolled rectifier), when the PWM rectifier starts to work at $0.1 \mathrm{~s}$, the DC voltage is regulated at $200 \mathrm{~V}$ because of its boost properties. It is also worth mentioning that, during the entire testing period, all the control and operative objectives set for the PWM rectifier were reached with only a one-loop controller, without the use of $d-q$ transformation and considering realistic unexpected simultaneous disturbances.

The PWM rectifier has been designed considering power consumption of $1.5 \mathrm{~kW}$ with the tolerances shown in Table 3. Considering constant current consumption with a constant, ripple-free DC voltage, the operation point of the system corresponds to $7.5 \mathrm{~A}$ and $200 \mathrm{~V}$, which provides $1.5 \mathrm{~kW}$. However,

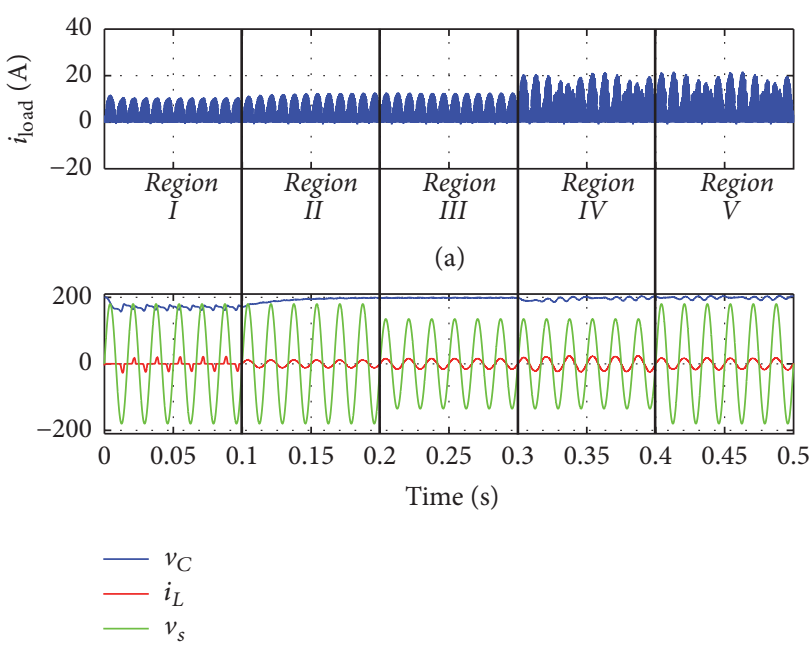

(b)

FIGURE 6: (a) Current consumption of the inverters. (b) DC voltage, $\mathrm{AC}$ current, and AC voltage.

the industrial applications impose dynamic loads and power quality problems. Therefore, it is normal to consider a certain margin of tolerance as a standard operation condition and then, only in terms of realistic performance, to establish an operation region in which the system will function as normal. Figure 7 shows a plot of $v_{C}$ versus $i_{\text {load }}$ considering all the scenarios shown in each region. As it can be observed, DC voltage is regulated inside the $10 \%$ tolerance, even during load transients or AC voltage sags. This is an important contribution of this work in terms of providing the system with robustness against undesirable events such as voltage sags, which are common in electrical networks.

\section{Conclusion}

In PWM rectifiers, it is very common to consider a two-loop control scheme in order to obtain a good dynamic response and output voltage regulation. At the same time, the $d-q$ 


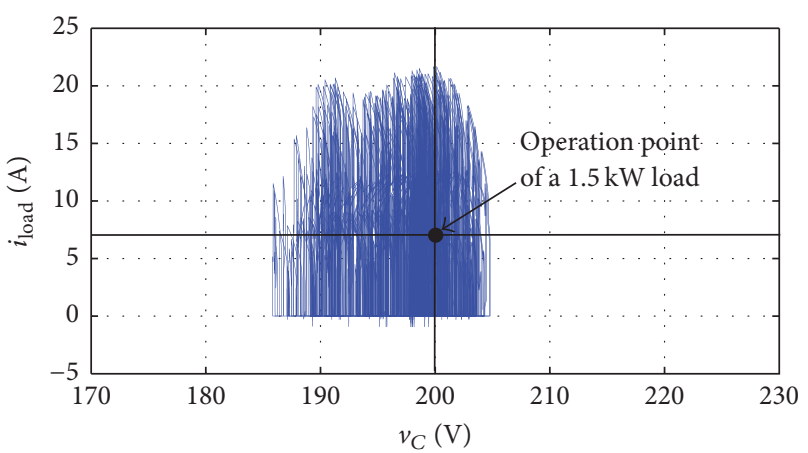

Figure 7: Operation region in terms of $v_{C}$ versus $i_{\text {load }}$. The limits of the scale in abscissa axis correspond to a maximum variation of $\pm 15 \%$ with respect to $200 \mathrm{~V}$.

synchronous frame has been widely applied to these systems either to obtain references or to transform the mathematical model. Such considerations have given good results but require more processing, meaning time delays which can be critical, especially in transient situations.

Although the use of control in $d-q$ frame has been reported with good results, in practical terms, frequency variations occur in electrical networks and they produce mathematical inconsistences in the transformation which generate a decreasing performance unless a perfect synchronization is carried out considering a computational effort. The control scheme proposed in this paper does not require any transformation; therefore performance is satisfactory even when frequency variations of the network occur.

This paper analyzes a different approach dependent on the feedback linearization-based nonlinear control and analyzing the stability of the system. Considering this approach, the authors explore the benefits of avoiding the $d$ - $q$ transformation applied to the model and they demonstrate the feasibility of providing the PWM rectifier with robustness and good dynamic response by using only a single-loop controller. Moreover, in order to show the capability of operating the system with strong variations, a set of simulation tests was performed considering realistic scenarios such as nonlinear dynamic loads and voltage sags. The results were very promising because the simulations revealed that, at any time, the control objectives initially established were reached.

\section{Conflicts of Interest}

The authors declare that they have no conflicts of interest.

\section{Acknowledgments}

This work was partially supported by CONACYT-SENER Grant no. 233755: Experimental Laboratory of DC Microgrids.

\section{References}

[1] M. Nishimoto, J. W. Dixon, A. B. Kulkarni, and B.-T. Ooi, "An integrated controlled-current pwm rectifier chopper link for sliding mode position control," IEEE Transactions on Industry Applications, vol. IA-23, no. 5, pp. 894-900, 1987.

[2] O. Stihi and B.-T. Ooi, "A single-phase controlled-current PWM rectifier," IEEE Transactions on Power Electronics, vol. 3, no. 4, pp. 453-459, 1988.

[3] Y. Zhang, Z. Li, Y. Zhang, W. Xie, Z. Piao, and C. Hu, "Performance improvement of direct power control of pwm rectifier with simple calculation," IEEE Transactions on Power Electronics, vol. 28, no. 7, pp. 3428-3437, 2013.

[4] A. El Magri, F. Giri, A. Abouloifa, and F. Z. Chaoui, "Robust control of synchronous motor through AC/DC/AC converters," Control Engineering Practice, vol. 18, no. 5, pp. 540-553, 2010.

[5] T.-C. Chen, T.-J. Ren, and J.-C. Ou, "Fixed switching frequency applied in single-phase boost AC to DC converter," Energy Conversion and Management, vol. 50, no. 10, pp. 2659-2664, 2009.

[6] P. Rioual, H. Pouliquen, and J. Louis, "Non linear control of pwm rectifier by state feedback linearization and exact pwm control," in Proceedings of the 25th Annual IEEE Power Electronics Specialists Conference, vol. 2, pp. 1095-1102, Institute of Electrical and Electronics Engineers, 1994.

[7] J. Espinoza, G. Joos, and L. Moran, "Decoupled control of the active and reactive power in three-phase PWM rectifiers based on non-linear control strategies," in Proceedings of the 30th Annual IEEE Power Electronics Specialists Conference, pp. 131136, Charleston, SC, USA.

[8] S. Somkun, P. Sethakul, and V. Chunkag, "Novel control technique of single-phase PWM rectifier by compensating output ripple voltage," in Proceedings of the 2005 IEEE International Conference on Industrial Technology, ICIT 2005, pp. 969-974, Institute of Electrical and Electronics Engineers, December 2005.

[9] Z. Zhang, Y. Xin, and W. Zhang, "A novel PWM rectifier control technique for on-line UPS under unbalanced load based on DSP," in Proceedings of the 27th Chinese Control Conference, CCC, pp. 695-699, Institute of Electrical and Electronics Engineers, China, July 2008.

[10] Z. Yin, J. Liu, and Y. Zhong, "Study and control of three-phase PWM rectifier based on dual single-input single-output model," IEEE Transactions on Industrial Informatics, vol. 9, no. 2, pp. 1064-1073, 2013.

[11] Z. Zhou, C. Wang, Y. Liu, P. M. Holland, and P. Igic, "Load current observer based feed-forward DC bus voltage control for active rectifiers," Electric Power Systems Research, vol. 84, no. 1, pp. 165-173, 2012.

[12] W. Chen, X. Geng, T. Liu, and C. Xia, "Stationary frame deadbeat power control of three-phase PWM rectifiers under unbalanced grid voltages," Electric Power Systems Research, vol. 108, pp. 223-233, 2014.

[13] C. Bian, C. Shi, C. Song, and A. Wang, "Study of the control system of three-level PWM rectifier based on virtual flux oriented," in Proceedings of the 3rd International Conference on Intelligent Human-Machine Systems and Cybernetics, IHMSC 2011, pp. 53-56, August 2011.

[14] A. Hadri-Hamida, A. Allag, M. Y. Hammoudi et al., "A nonlinear adaptive backstepping approach applied to a three phase PWM AC-DC converter feeding induction heating," Communications in Nonlinear Science and Numerical Simulation, vol. 14, no. 4, pp. 1515-1525, 2009.

[15] R. Sierra, V. Cárdenas, J. Alcalá, and N. Visairo, "Single-phase analysis of BTB converter under unbalanced voltage conditions," in Proceedings of the 2011 8th International Conference 
on Electrical Engineering, Computing Science and Automatic Control, CCE 2011, pp. 1-6, Institute of Electrical and Electronics Engineers, Mexico, October 2011.

[16] D.-C. Lee, G.-M. Lee, and K.-D. Lee, "DC-bus voltage control of three-phase ac/dc PWM converters using feedback linearization," IEEE Transactions on Industry Applications, vol. 36, no. 3, pp. 826-833, 2000.

[17] T.-S. Lee, "Input-output linearization and zero-dynamics control of three-phase AC/DC voltage-source converters," IEEE Transactions on Power Electronics, vol. 18, no. 1 I, pp. 11-22, 2003.

[18] J. Lira, V. Cirdenas, and C. Nunez, "Analysis and design of a PWM rectifier using the DQ theory and a digital control based in a DSP," in Proceedings of the 9th IEEE International Power Electronics Congress, 2004. CIEP 2004, pp. 52-57, Institute of Electrical and Electronics Engineers, Celaya, Mexico.

[19] J. Lira, V. Cardenas, and C. Nunez, "Factor compensation capacity," in Proceedings of the (ICEEE) 1st International Conference on Electrical and Electronics Engineering, 2004, pp. 567572, Institute of Electrical and Electronics Engineers, Acapulco, Mexico.

[20] J. Zhou and X. Lu, "Review of Exact Linearization Method Applied to Power Electronics System," in Proceedings of the 2012 IEEE PES Asia-Pacific Power and Energy Engineering Conference (APPEEC), pp. 1-4, Institute of Electrical and Electronics Engineers, Shanghai, China, March 2012.

[21] M. Jamma, M. Barara, M. Akherraz, and B. A. Enache, "Voltage oriented control of three-phase PWM rectifier using space vector modulation \& input output feedback linearization theory," in Proceedings of the 8th International Conference on Electronics, Computers and Artificial Intelligence, ECAI 2016, pp. 17-23, Ploiesti, Romania, July 2016.

[22] N. Muangruka and S. Nungam, "Direct power control of threephase voltage source converters using feedback linearization technique," Procedia Computer Science, vol. 86, pp. 365-368, 2016.

[23] M. Deng, H. Yu, S. Bi, and S. Wen, "New developments on robust nonlinear control and its applications," Mathematical Problems in Engineering, vol. 2014, Article ID 463294, 2 pages, 2014.

[24] N. Visairo, C. Nunez, J. Lira, and I. Lazaro, "Avoiding a voltage sag detection stage for a single-phase multilevel rectifier by using control theory considering physical limitations of the system," IEEE Transactions on Power Electronics, vol. 28, no. 11, pp. 5244-5251, 2013.

[25] A. Isidori, Nonlinear Control Systems, Springer, 3rd edition, 1995.

[26] H. K. Khalil, "Nonlinear Systems," Prentice Hall, New York, NY, USA, 3rd edition, 2002. 


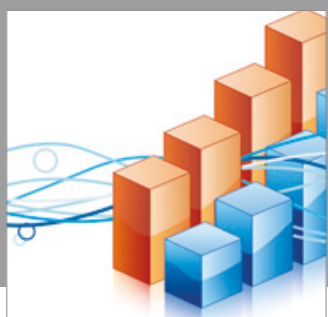

Advances in

Operations Research

vatersals

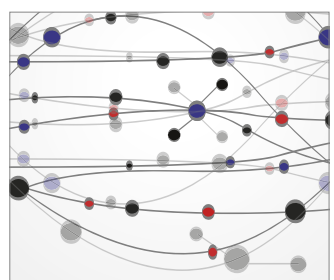

\section{The Scientific} World Journal
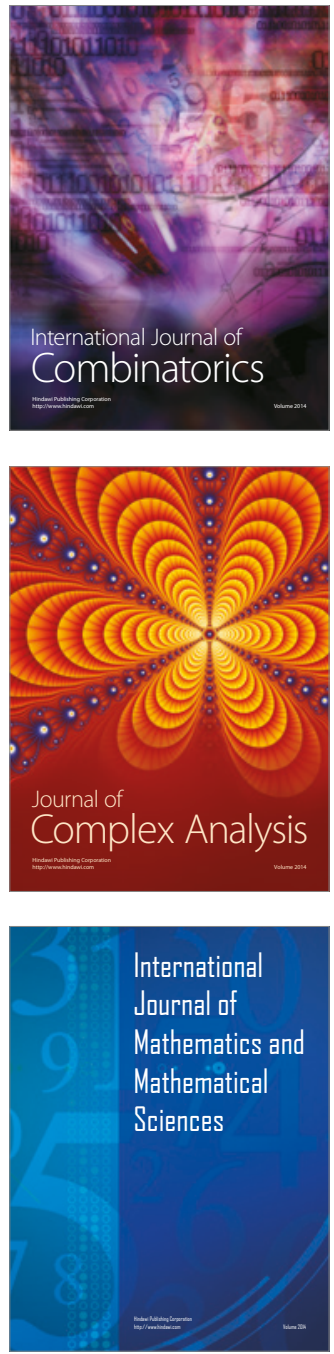
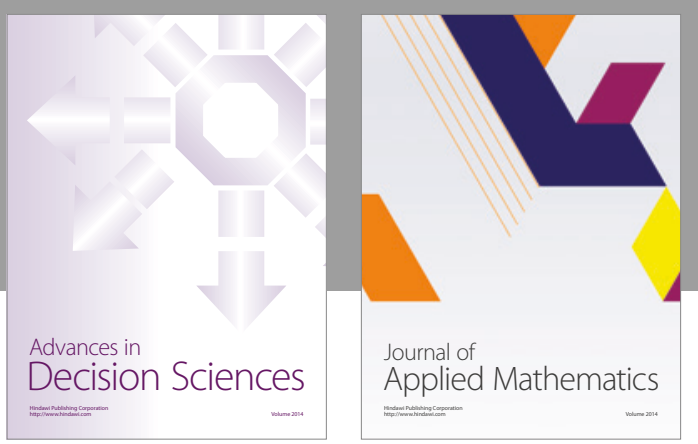

Algebra

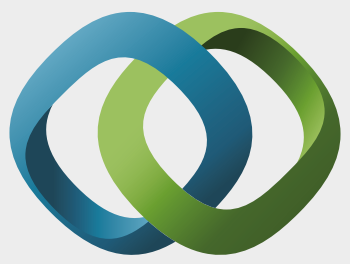

\section{Hindawi}

Submit your manuscripts at

https://www.hindawi.com
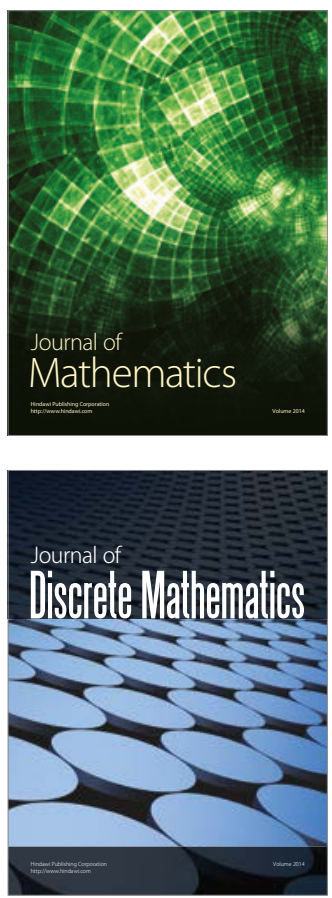

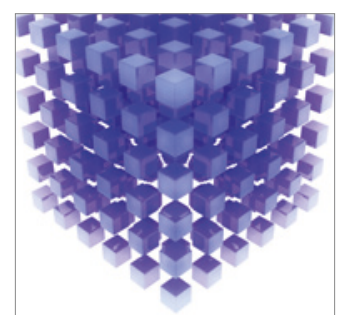

Mathematical Problems in Engineering
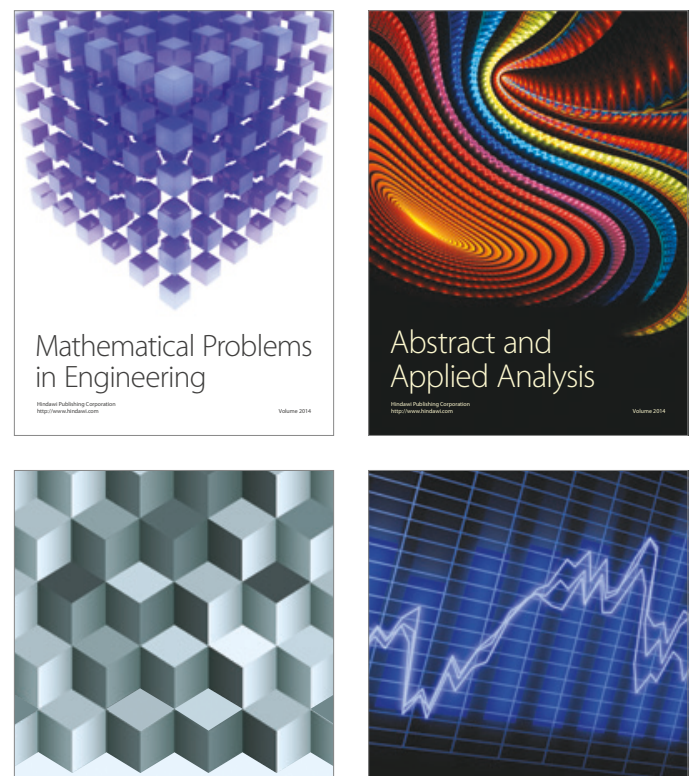

Journal of

Function Spaces

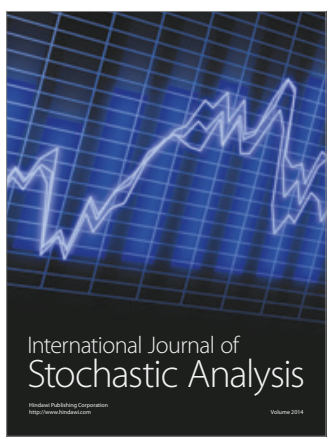

Probability and Statistics
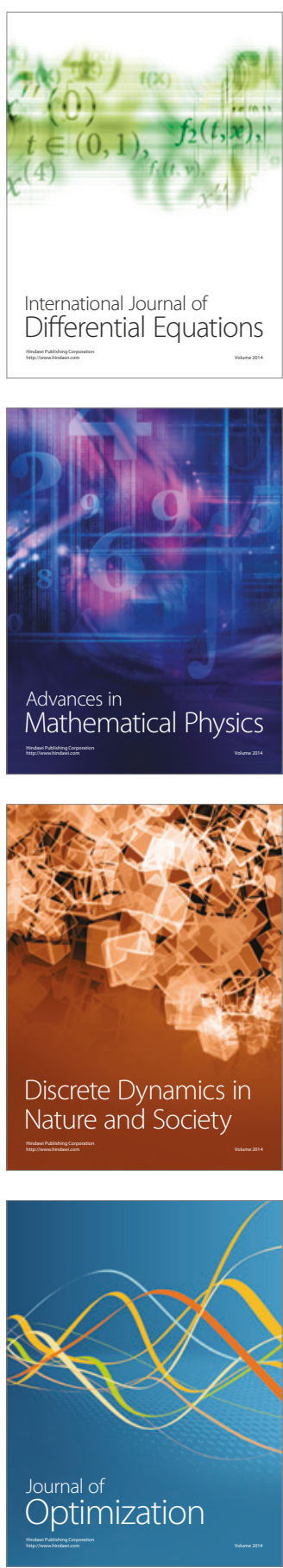